\title{
Study on the Importance of Protecting the Original Artistic Value of the Cultural Heritage of the Mogao Grottoes
}

\author{
Shuyan Pei ${ }^{1, *}$ Yuxin $\mathrm{He}^{2}$
}

\author{
${ }^{1}$ Northwest University, Xi'an, China \\ ${ }^{2}$ School of Historical Culture and Tourism, Xi'an University, Xi'an, 710065 China \\ *Corresponding author. Email: 1131692128@qq.com
}

\begin{abstract}
The mural paintings in Mogao Grottoes have high historical, artistic and cultural values. In the course of thousands of years, they have been affected by various natural and human factors, resulting in the emergence of different kinds of diseases. It is very important to carry out the work of disease control and restoration of mural paintings. At the same time, the application of digital technology has played a great role in the protection of murals in Mogao Grottoes. In this paper, the management and protection of mural diseases in Mogao Grottoes are studied, and the application of digital technology is introduced and prospected.
\end{abstract}

Keywords: Mogao Grottoes, diseases of murals, governance protection, digital technology

\section{INTRODUCTION}

There are a large number of exquisite murals in the Mogao Grottoes of Dunhuang. These murals have very precious historical, artistic, cultural and technological values. In addition, they have important practical significance for the study of China's painting art, ancient society, and traditional culture and so on. However, since the creation of Mogao Grottoes in Dunhuang, under the influence of many natural and human factors, different kinds of diseases have appeared on the murals. These diseases not only destroy the artistic and integrity of the murals, but also endanger the safety of the murals. Therefore, it is of great significance to study the treatment and repair of the diseases for the long-term preservation of the murals in Mogao Grottoes.

In the past few decades, the workers of Mogao Grottoes in Dunhuang and experts in China and foreign countries have studied the diseases of murals, and have taken a series of measures to carry out the treatment and restoration of murals. In addition, the application of modern digital technology plays an important role in the protection and restoration of murals, and has an important value for the protection of murals in the future.

\section{INTRODUCTION AND ARTISTIC VALUE OF} CULTURAL HERITAGE OF MOGAO GROTTOES

Mogao Grottoes at Dunhuang is one of the important parts of Dunhuang grottoes. It is located at the foot of Mingsha Mountain, Dunhuang City, Gansu province. It was built in the second year during Jianyuan Period of pre-Qin Dynasty (306 AD). Although it has gone through more than 1600 years, there are still 735 Grottoes from the late period of sixteen countries to the Yuan Dynasty. There are more than 45000 square meters of murals and more than 2000 painted sculptures [1]. In addition, more than ten thousand pieces of cultural relics such as scriptures and documents have been unearthed in the cave. The Mogao Grottoes also retain the relatively complete eaves of the wooden structure in the Tang and Song Dynasties, providing precious material materials for the study of the ancient buildings of wooden structure.

The content of murals in Mogao Grottoes is closely related to their geographical location. Dunhuang is located in the western end of Hexi Corridor. Until the Tang Dynasty, Dunhuang was the only place along the Silk Road, known as the "throat place". In the Han Dynasty, from Dunhuang to the East, people can reach Chang'an, Luoyang and other places; to the west, people can reach Xinjiang; and then to the west, people can reach Persia and other places after passing the Pamirs Plateau; to the north, people can reach the Northern Tianshan Mountain, which is an important traffic center on the ancient Silk Road. It is precisely 
because of this special geographical location that the cultures of different places converge here, and the fusion of Chinese and Western cultures has made the murals of Mogao Grottoes present a unique style. Cave 285 in Western Wei Dynasty is a typical example. The west wall presents a mellow and subtle Western style, the north, south and east walls present a bright and cheerful style of Central Plains, and the two styles on top are intermingled with each other [2].

The most representative of Dunhuang Grottoes art should be the murals of Mogao Grottoes, not only because of the largest number of Mogao Grottoes, but also the content involved is extensive. There are paintings depicting flying Apsaras in the murals, pictures reflecting the production of the working people at that time, as well as a large number of paintings depicting landscape, flowers and pavilions. Among them, the murals are roughly divided into 7 categories according to their contents: Buddhist paintings, Story paintings, paintings of Buddhist content, traditional mythological paintings, Portrait painting, landscape painting.

"Buddha painting" is an image for people to worship. It is mainly based on the statement of Buddha, such as the "Luyeyuan Falun" picture on the north wall of Cave 236. This is the image of the first statement after the Buddha found Taoist. "Story painting" and "paintings of Buddhist content" are murals that spread Buddhist ideas to people, such as the painting of Saki sacrificing his body to feed a tiger in cave 254, which publicizes the idea of "sacrificing oneself and saving all living beings". Traditional theme paintings are often combined with Buddhist story paintings, reflecting the integration of foreign thoughts and culture with local Confucianism and Taoism. The decorative patterns are mainly flat base and caisson. The common patterns are lotus pattern, honeysuckle pattern, bird and beast pattern, pattern of gods and monsters flying in the sky, etc. It belongs to the category of portrait painting. It is not only a work of art, but also provides a lot of important historical data for the research work. At the same time, the clothes in the mural are based on real people, so it also provides data for the study of the history of clothing [2]. The content and form of "landscape painting" is very rich, among which the "Wutai Mountain" on the west wall of cave 61 is the representative. This picture draws a panoramic view of Wutai Mountain and the surrounding mountains and rivers, pavilions and buildings within $800 \mathrm{li}$, so it is also a hologram of geography. At the same time, it also proves that China is the first country to use perspective painting techniques, with high artistic value and historical value.

Because most of the Dunhuang Grottoes are built by the people themselves, the murals in Mogao Grottoes largely reflect the superb painting skills of the folk painters in China. At the same time, these painters mostly create the murals according to the wishes of the owners of the grottoes and their own understanding of the Buddhist figures and stories, which provides very important materials for the study of the spread and evolution of ancient folk aesthetic and religious thoughts.

\section{THE WORK FOR THE RESTORATION AND RESEARCH OF THE CULTURAL HERITAGE OF MOGAO GROTTOES AND ITS IMPORTANCE}

Since the opening of Mogao Grottoes in Dunhuang, it has experienced thousands of years. Under the influence of various natural and human factors, the murals of Mogao Grottoes have suffered different degrees of damage. After the closure of Jiayuguan in Ming Dynasty, Dunhuang has almost become a desolate border area. Under this historical background, Mogao Grottoes have been in the situation of no attention for about 500 years. Therefore, Mogao Grottoes have not been protected in this period of time and can only be allowed to be eroded by wind and sand. In addition, there are a series of factors, such as natural collapse, theft and destruction, which made the grottoes a scene of dilapidation in the 1940s. Meanwhile, the murals in the grottoes were also seriously damaged.

The main causes of the mural diseases in Mogao Grottoes are: the pollution and wear of the mural caused by the sand erosion of the surrounding environment, the fading of the pigments used in the mural itself, and the diseases caused by the soluble salts caused by the collapse and seepage of the rock mass. Also, the smoke and incense fires made by the people who lived in the grottoes in the past caused the mural to turn black and unrecognizable, as well as the artificial depiction and painting of the mural, the integrity of the mural is destroyed.

The most harmful to the murals in Mogao Grottoes is various diseases caused by salts, such as salt efflorescence, flaking, falling off, hollowing, herpes, etc. The repair time of hollow disease is relatively early. For example, the restoration work of hollow murals in cave 130 was carried out in 1965 . At that time, the method of combining sticking with pulling anchor was adopted to strengthen the hollow murals. After continuous research, combined with field test and simulation experiment and the ancient methods of controlling the hollow murals, the main methods to solve the hollow murals were summarized as grouting combined anchorage [3]. Among the diseases of salt damage, the problems of salt efflorescence and flaking are the most serious and the most difficult to control in the murals of Mogao Grottoes. The repair materials for the flaking of murals have been studied since the early days. After a long-term scientific and systematic screening and determination of the repair materials for 
the flaking of murals, they have been successfully applied to the repair of the flaking of murals. However, the flaking of murals is often accompanied by salt efflorescence. Because of the salt efflorescence on the ground, the powder layer or pigment layer of murals will lose its cementation with the ground, resulting in the same pigment layer peeling together with the powder layer. The reason for the salt efflorescence of murals is that the soluble salt in rock mass and ground is produced under the action of water environment, so the key to control the salt efflorescence of murals is to control the source of water in the Grottoes. Therefore, it has made many actions, such as taking crack grouting, making anti-seepage wall (layer), placing hygroscopic agent in the grottoes and so on [4], so as to control the hydrological environment in Mogao Grottoes.

Salt damaged murals have always been the difficulty in the restoration of murals in Mogao Grottoes. For this reason, after a long-term investigation and monitoring of the surrounding environment, the workers put forward a specific method for the treatment of soluble salt and salt damaged murals, and made a lot of research on the restoration technology of damaged murals, and developed new materials of high water absorption and salt absorption resin. Although some progress has been made in the restoration and treatment of mural diseases in Mogao Grottoes, there are still many deficiencies in the research process, such as: how to achieve nondestructive testing in the study of mural diseases, and how to strengthen the control of the micro environment of the grottoes. There are also many problems in the treatment and repair of mural diseases, which are basically technical problems. For example, it is difficult to sample materials such as $\mathrm{Na} 2 \mathrm{SO} 4$ in mural diseases; new materials encounter the influence of various variables when they are used; now the treatment and repair of mural diseases are still in a passive situation, so it is very important to take the initiative in the prevention and repair of mural diseases. However, it can't be realized now. To solve these problems, there is still "a long way to go" for the current research work.

The murals in Mogao Grottoes are non-renewable. In the face of the situation that Mogao Grottoes are disappearing gradually in a very slow but irreversible situation, the treatment and repair of mural diseases is very important for the long-term preservation of the murals in Mogao Grottoes.

\section{MEASURES TO PROTECT THE CULTURAL HERITAGE OF MOGAO GROTTOES}

From the establishment of the national Research Institute of Dunhuang Art in 1944 to later Dunhuang Research Institute with the expansion, many experts and scholars have made outstanding contributions to the protection of Mogao Grottoes. Since the establishment of Dunhuang Research Institute, the research on the protection of Dunhuang Grottoes has gradually entered a new stage.

After Dunhuang Grottoes were successfully declared as world cultural heritage sites, the staff of Dunhuang Research Institute increased international exchanges and cooperation, and constantly learned and introduced new ideas and advanced science and technology, so as to strengthen the protection of Dunhuang Grottoes. With the help of UNESCO representatives in China, Dunhuang Research Institute has cooperated with other international cultural relics protection research institutions such as the Getty foundation and its Conservation Institute. During the period of cooperation with the Getty Conservation Institute, the following works were carried out to promote the protection of murals in Mogao Grottoes: the establishment of a full-automatic meteorological station in Mogao Grottoes; the monitoring, research and control of the sandstorm around Mogao Grottoes; the strengthening of the monitoring of the micro environment of the open Grottoes; the research and investigation of the materials and diseases of murals and the equipping of instruments and equipment for the protection research; investigation and research on natural and human factor threatening the protection of Mogao Grottoes; experimental production of Dunhuang digital archives for permanent preservation of Mogao Grottoes murals [5].

In order to further control the damage caused by human factors to the murals of Mogao Grottoes, and to cooperate with the work of tourism opening, Dunhuang Research Institute has taken a new management measure of tourism opening, that is, to start to implement the "visit diversion". This measure is adopted according to accurate scientific data provided by Dunhuang Research Institute and Getty Conservation Institute to jointly monitor the micro environment of the open grottoes, as well as the research on the carrying capacity of tourists. In order to avoid the damage to the murals in the grottoes as much as possible, the relative humidity in the open grottoes of Mogao Grottoes shall not exceed 62\%, the carbon dioxide content shall not exceed $1500 \mathrm{ppm}$, the open Grottoes shall not be less than 13 square meters, each batch of visitors shall not exceed 25 , and the maximum daily tourist capacity of Mogao Grottoes is 3000 [5]. In addition, in order to meet the needs of more and more tourists, Dunhuang Research Institute launched the "digital Dunhuang" project.

In 2003, Mr. Fan Jinshi ${ }^{1}$, the honorary president of Dunhuang Research Institute, proposed to use modern

Fan Jinshi (1938-), female, native of Shanghai, honorary president of Dunhuang Academy, researcher, director of the Central Museum of Literature and History. 
technology to strengthen the protection and development of Mogao Grottoes. After a long period of exploration under the leadership of Mr. Fan Jinshi, the "digital Dunhuang" was initially realized under the support of digital technology. With the application of digital technology in the protection of murals in Mogao Grottoes, the permanent storage of mural material data into picture data has been achieved. Another important aspect is the application of virtual reality (VR) technology, that is, the use of three-dimensional reproduction of layered murals, high fidelity and other technologies to reproduce the real scene of murals in Mogao Grottoes [6], which is also an important part of "digital Dunhuang". Dunhuang Research Institute has cooperated with research institutions in China and foreign countries to create three-dimensional models in the Grottoes by using virtual reality technology. Until September 2014, digital exhibition centers such as Dunhuang tourist reception hall and digital cinema built by Dunhuang Research Institute were officially opened to the public. Partly, the digital exhibition center is responsible for the diversion work of Mogao Grottoes, so that tourists can watch movies first, and then visit, so as to reduce the time tourists stay in the grottoes to strengthen the protection of murals in the grottoes. The other part is to let tourists watch 4D movies, such as those made by digital technologies, to show tourists the inside of the caves in an all-round way. And they can know more about the Mogao Grottoes. The murals of Mogao Grottoes reproduced in the digital exhibition center can show the details of the murals to the tourists more clearly. At the same time, because the virtual reality technology itself has immersion, interaction and imagination [7], it can greatly enhance the overall visitors' experience.

The application of digital technology can not only better popularize the culture of Mogao Grottoes to tourists, but also further solve the contradiction between the protection and management of cultural relics in Mogao Grottoes. The digitalization of murals in Mogao Grottoes is a big step forward to the concept of "sustainable use, permanent preservation".

\section{CONCLUSION}

The treatment of mural diseases in Mogao Grottoes can be divided into three stages

In the first stage, it is mainly to protect the Dunhuang Grottoes at the beginning of the establishment of the national Institute of Dunhuang Art Research. At that time, facing the murals that have already suffered from diseases, due to the limitations of technical conditions, people can only do some basic work, such as clearing quicksand, building plank road, installing protective doors, so as to reduce the impact of the surrounding environment on the murals of the grottoes.
In the second stage, after the establishment of Dunhuang Research Institute, it began to strengthen the research on the protection of Dunhuang Grottoes. Experts took reinforcement measures for the cliff body and grottoes of Mogao Grottoes, and began to use some new materials and technologies to repair the damaged murals in the grottoes, and carried out sand prevention and control work around the grottoes, and established a meteorological observation station inside the grottoes to monitor the micro environment in real time.

In the third stage, with the successful application for cultural heritage, the management and protection of Mogao Grottoes were more scientific. Dunhuang Research Institute has strengthened international cooperation to carry out comprehensive management of Mogao Grottoes. The most important thing is to establish cultural relics archives of Mogao Grottoes murals by applying digital information technology to achieve permanent preservation.

As for the protection of murals in Mogao Grottoes, there are also the following suggestions and prospects:

\section{A. Maintaining international exchanges and cooperation}

The case of Dunhuang Research Institute's cooperation with the U.S. cultural relics protection research institute in the past proves the necessity of international cooperation in the face of the protection of murals in Mogao Grottoes. For the management and protection of the murals in Mogao Grottoes, in addition to the introduction of foreign new materials and technologies, it is necessary to actively participate in the discussion and exchange. It can learn some new experience and new methods of foreign mural restoration, and then promote the improvement of mural restoration and protection skills.

\section{B. Increasing the application of science and technology (taking virtual reality technology as an example)}

With the development of science and technology, the application of virtual reality technology is more and more extensive. The virtual Imperial Palace roaming system developed by Zhejiang University shows the general layout of the roaming system and the overview of each palace [8]. Virtual reality technology is also changing the archeological model, such as the establishment of Dunhuang digital museum. People can learn from these successful cases and use 3D modeling technology to create a roaming system for the murals in Mogao Grottoes [9]. In addition, using virtual reality technology to carry out simulation experiments before the actual restoration of murals may reduce the operational errors in the actual restoration process. Also, people can increase the possibility of mural 
restoration through the realization of simulation operations.

Although there are still many unsolved problems in the research of virtual reality technology, the application of virtual reality technology is undoubtedly of far-reaching significance to the protection of murals in Mogao Grottoes and the promotion and dissemination of Mogao Grottoes culture.

\section{Increasing promotion and publicity}

From the perspective of promotion and publicity, the protection of the murals in Mogao Grottoes is mainly to increase the attention of the masses. It hopes to have more professionals in the protection of murals, who can invest in the relevant work of the protection of murals in Mogao Grottoes.

In addition, how to use more forms to develop and utilize the mural elements of Mogao Grottoes is also very important, such as the dance drama "Silk Road Stories" created according to the flying Apsaras in the mural of Mogao Grottoes, the cultural products like silk scarves made by using the mural elements of Mogao Grottoes and so on, which are loved by the masses. With the application of digital technology, there are two directions for the development of cultural and creative products [10]. In the development of virtual cultural and creative products, it can learn from the experience of the Palace Museum, such as the Emperor's Day app developed by the Palace Museum. Recently, the Forbidden City has realized the transformation from cultural creation to the public through the program "Updating · Forbidden City", which cooperates with the TV station. These new attempts have expanded ideas for the external publicity of Dunhuang Mogao Grottoes culture.

\section{References}

[1] Fan Jinshi. Protection and management of Mogao Grottoes in Dunhuang [J]. Dunhuang Research, 2000 (1): 1-4. (in Chinese)

[2] Duan Wenjie. Art of Dunhuang Grottoes in the Sixteen Kingdoms and Northern Dynasties [C]. Lanzhou: Gansu People's Publishing House, 1982: 7-26. (in Chinese)

[3] Li Zuixiong. The status of protecting Dunhuang Grottoes and tasks [J]. Dunhuang Research, 2000 (01): 10-23. (in Chinese)

[4] Chen Gangquan. Analysis and treatment of salt damage in frescoes of Mogao Grottoes in Dunhuang [D]. Lanzhou University, 2016: 23-29. (in Chinese)

[5] Fan Jinshi. Exploration and Practice in the Conservation and Management of the Dunhuang Mogao Grottoes [J]. Dunhuang Research, 2016 (05): 1-5. (in Chinese)

[6] Hu Bing. Digital Dunhuang: A New Approach to Cultural Heritage Protection in the New Era [N]. China Social Science News, 2018-11-29 (007). (in Chinese)

[7] Cai Cai, Song Shuangshuang. Application of Virtual Reality Technology in the Dunhuang Frescoes Protection [J]. Science and Technology \& Innovation, 2015 (11): $78+81$. (in Chinese)
[8] Guan Dandan. Visual simulation and interactive design of virtual scenes of ancient sites [D]. Xi'an Polytechnic University, 2013. (in Chinese)

[9] Wang Xiaoyu. Research on immersive virtual 3D scene reconstruction technology of Mogao Grottoes in Dunhuang [D]. Xi'an Polytechnic University, 2016. (in Chinese)

[10] Wu Yuanfang. Research on the development of cultural and creative products based on Dunhuang frescoes [D]. Lanzhou University, 2019. (in Chinese) 